\title{
CPR Guidance by an Emergency Physician via Video Call: A Simulation Study
}

\author{
Dong Keon Lee $\mathbb{D}^{1},{ }^{1}$ Seung Min Park ${ }^{D},{ }^{1}$ Yu Jin Kim, ${ }^{1}$ Choung Ah Lee, ${ }^{2}$ Won Jung Jeong, \\ Gi Woon Kim, ${ }^{4}$ Dong Hyuk Shin, ${ }^{5}$ and Young Hwan Lee ${ }^{4}{ }^{4}$ \\ ${ }^{1}$ Department of Emergency Medicine, Seoul National University Bundang Hospital, Gyeonggi-do, Republic of Korea \\ ${ }^{2}$ Department of Emergency Medicine, Dongtan Sacred Heart Hospital, Hallym University School of Medicine, \\ Hwaseong, Republic of Korea \\ ${ }^{3}$ Department of Emergency Medicine, The Catholic University of Korea, St. Vincent's Hospital, Suwon, Gyeonggi-do, Republic of Korea \\ ${ }^{4}$ Department of Emergency Medicine, College of Medicine, Soonchunhyang University, Bucheon, Gyeonggi-do, Republic of Korea \\ ${ }^{5}$ Department of Emergency Medicine, Kangbuk Samsung Hospital, Sungkyunkwan University School Medicine, \\ Seoul, Republic of Korea
}

Correspondence should be addressed to Seung Min Park; aukawa1227@gmail.com and Young Hwan Lee; zerohwani@gmail.com

Received 22 August 2018; Revised 20 October 2018; Accepted 12 November 2018; Published 29 November 2018

Academic Editor: Chak W. Kam

Copyright (C) 2018 Dong Keon Lee et al. This is an open access article distributed under the Creative Commons Attribution License, which permits unrestricted use, distribution, and reproduction in any medium, provided the original work is properly cited.

\begin{abstract}
Background. In South Korea, the prehospital treatment of cardiac arrest is generally led by an emergency medical technicianparamedic (EMT-P), and defibrillation is delivered by the automatic external defibrillator (AED). This study aimed at examining the effects of direct medical guidance by an emergency physician through a video call that enabled prompt manual defibrillation. Methods. Two-hundred eighty-eight paramedics based in Gyeonggi Province were studied for four months, from July to November 2015. The participants were divided into 96 teams, and the teams were randomly divided into either a conventional group that was to use the AED or a video call guidance group which was to use the manual defibrillators, with 48 teams in each group. The time to first defibrillation, total hands-off time, and hands-off ratio were compared between the two groups. Results. The median value of the time to the first defibrillation was significantly shorter in the video call guidance group (56 s) than in the conventional group $(73 \mathrm{~s})(\mathrm{p}<0.001)$. The median value of the total hands-off time was also significantly shorter $(228 \mathrm{vs} .285 .5 \mathrm{~s})(\mathrm{p}<0.001)$, and the hands-off ratio, defined as the proportion of hands-off time out of the total CPR time, was significantly shorter in the video call guidance group ( 0.32 vs. 0.41$)$ ( $\mathrm{p}<0.001)$. Conclusion. Physician-guided CPR with a video call enabled prompt manual defibrillation and significantly shortened the time required for first defibrillation, hands-off time, and hands-off ratio in simulated cases of prehospital cardiac arrest.
\end{abstract}

\section{Introduction}

In South Korea, the rates of restoration of spontaneous circulation (ROSC) following cardiac arrest in 2012-2015 were $5.1 \%$ and $23.1 \%$ before and after hospital arrival, respectively, while the rate of survival to hospital discharge among patients who were hospitalized after the acute cardiac arrest was merely 5.0\% [1]. Further, the proportion of patients who were discharged with the good neurological outcome (cerebral performance categories 1,2 ), which is the final resuscitation goal for out-of-hospital cardiac arrest patients, was only $2.3 \%$. This is an extremely low rate compared to the rate of $6.9 \%$ reported in the U.S. nationwide CARES study from 2005 to
2010 and $8.9 \%$ reported in a Japanese study conducted in Osaka from 2007 to 2009 [2, 3].

In South Korea, as physicians are not staffed in 119ambulances, the prehospital treatment is generally led by an emergency medical technician-paramedic (EMT-P) and manual defibrillator use, advanced airway insert, and intravenous line placement are not allowed to EMT-Ps without the physician's direct medical control in point of law.

In the prehospital cardiac arrest, physician-guided CPR is controversial as to whether there is survival benefit compared to paramedic-guided CPR. However, some studies reported that during $C P R$, the presence of physicians had 


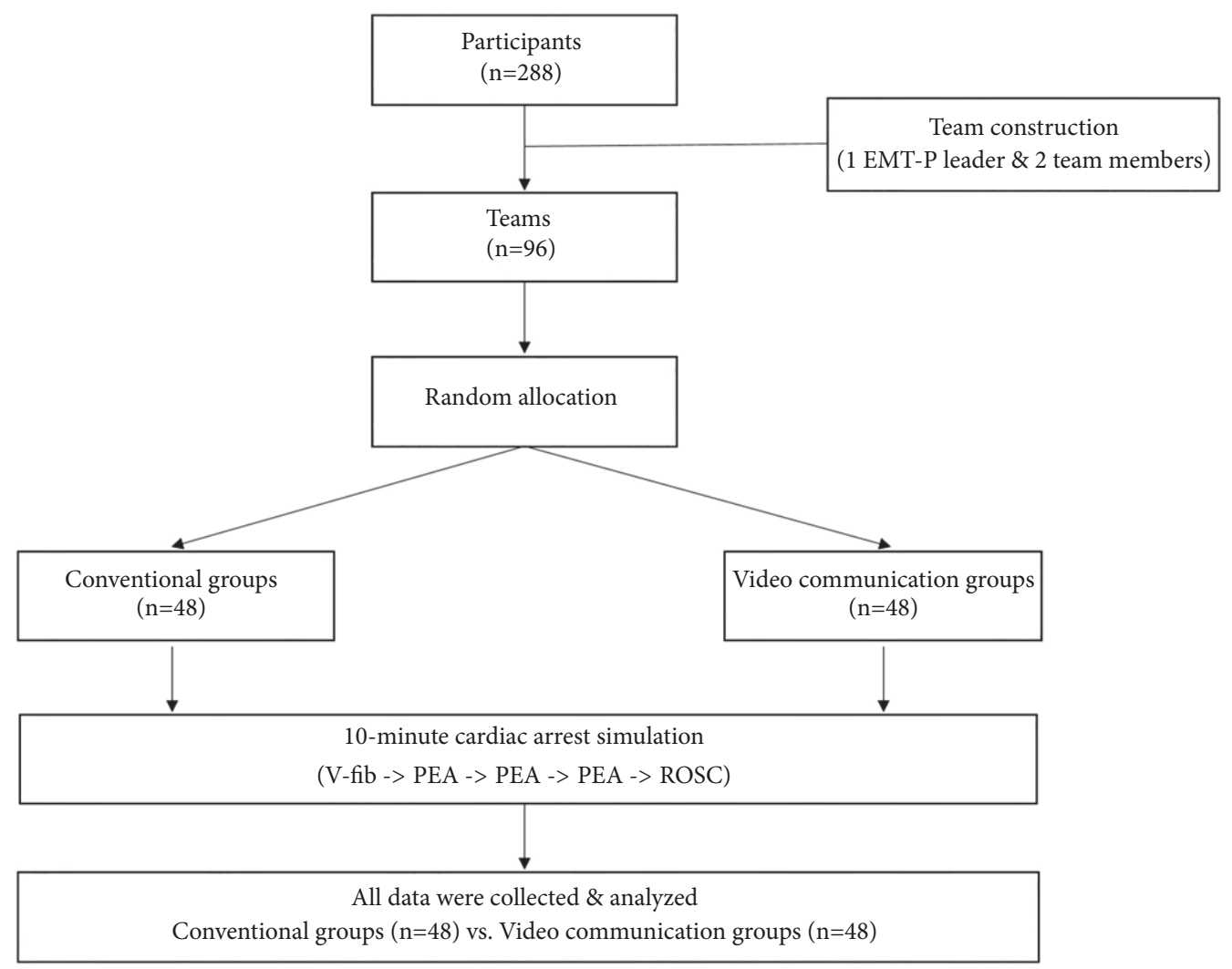

FIGURE 1: Flow diagram of the study.

been reported to increase compliance with the guidelines that could lessen the hands-off time [4-9]. Moreover, in a simulation study by Pytte et al., both the times from the last compression to defibrillation and from defibrillation to chest compression were shorter with manual defibrillators than with AEDs, which was also supported by a retrospective study on actual patients by Kramer-Johansen et al. [10, 11].

Taken together, these studies indicate that prolonged pause of chest compression reduces the coronary and cerebral perfusion pressure, which may have deleterious consequences for the patient.

Recent advances in video call technology have enabled remote monitoring of cardiac arrest status through smartphones. One previous study that examined the differences in the quality of dispatcher-assisted chest compression between video coaching and audio coaching and the video coaching showed better results regarding the compression rate, the accuracy of the compression site, and the minimisation of the hands-off time [12].

Based on these previous studies and the current situation in South Korea, the present study aimed at examining the effects of direct medical guidance by an emergency physician through a video call and the effect of the manual defibrillator use.

\section{Methods}

2.1. Study Participants and Design. Two-hundred and eightyeight paramedics based in Gyeonggi-do Province were studied for four months, from July to November 2015. The participants were divided into 96 teams of one EMT-P leader and two team members, and the teams were randomly divided into either a group using the AEDs (conventional group) or a group using manual defibrillators with video guidance by a physician (video call guidance group), with 48 teams in each group (Figure 1).

Ninety-six teams of EMT-P were trained for eight hours on video-guided CPR in theory and practice. The training was conducted for three months, considering the working hours of paramedics. After training, the simulations were conducted four times a day for a month at the simulation centre in a tertiary university hospital located downtown and videorecorded using an SMX-F34 camcorder (Samsung, South Korea), with consent from the trainees. The ALS Simulator (Laerdal, Norway) and Biphasic defibrillator-monitor Dixion HD-1 (Dixion, Germany) were used for the simulations.

In the simulation scenarios, EMTs were dispatched after receiving a call for cardiac arrest. The participants in the conventional group performed cardiopulmonary resuscitation with $\mathrm{AED}$, and the members in the video call guidance group connected the video call just before scene arrival to perform cardiopulmonary resuscitation with manual defibrillators with a physician's real-time direct medical control via the video call. For the video call, one EMT-P leader held the phone to communicate with the guiding physician and show the cardiac rhythm on the defibrillator, the overall situation to the guiding physician (Figure 2). Galaxy S6 (Samsung, South 


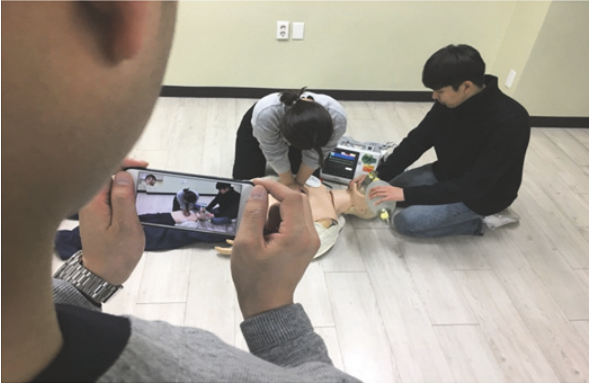

(a)

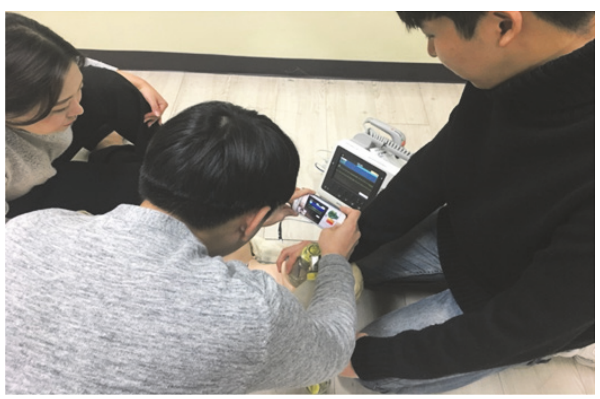

(c)

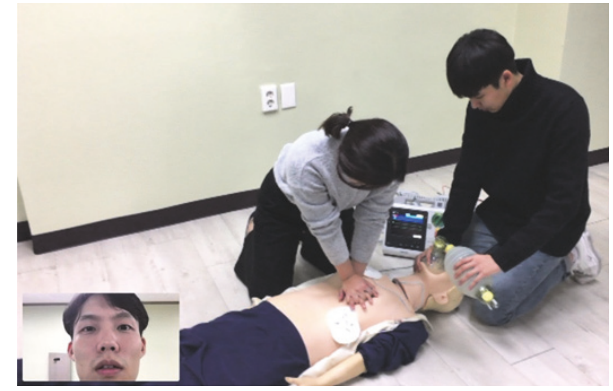

(b)

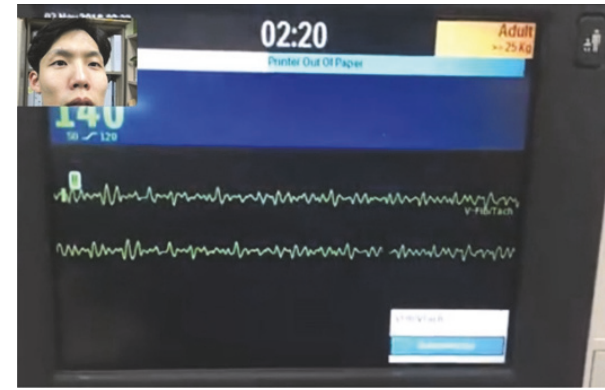

(d)

FIGURE 2: The video call for the physician's real-time direct medical control. (a) The EMT-P leader held the phone to show the overall situation to the guiding physician. (b) The guiding physician's view of the overall situation. (c) The EMT-P leader shows the cardiac rhythm on the defibrillator to the physician, the overall situation to the guiding physician. (d) The guiding physician's view of the cardiac rhythm on the defibrillator.

Korea), which supports long-term evolution (LTE), was used for a video call connection.

A total of six emergency physicians were involved in this study. One guiding physician participated per scenario, and the cardiac rhythm was analyzed every two minutes. Ninetysix clinical case scenarios were done, which had the same 10-minute simulation of the following protocol: ventricularfibrillation $->$ pulseless electrical activity (PEA) -> PEA -> PEA -> ROSC. Two persons other than the guiding physicians manipulated the cardiac rhythms so guiding physicians could be blinded to the cardiac rhythm flow. The role of the guiding physician involved was to guide the trainees in using the manual defibrillator according to the arrest rhythm and encourage them to shorten the hands-off time. The EMTs and guiding physicians were in different rooms and only communicated via video call.

2.2. Outcome Measures and Assessment. The primary outcomes were the time from arrival to the first defibrillation and the hands-off ratio. Secondary outcomes included the time from the last compression to defibrillation and the time from defibrillation to chest compression. To ensure consistency in the assessments, two advanced cardiovascular life support instructors who were not involved in the study assessed and scored each item while viewing the recorded video.

2.3. Statistical Analysis. Categorical data are expressed as the number and frequency. Continuous data are presented as the mean and standard deviation, median with interquartile range, or mean and range. Differences between the two groups were tested using the independent two-sample ttest or Mann-Whitney $U$ test for continuous variables, and the chi-square or Fisher's exact test was used for categorical variables. $\mathrm{p}<0.05$ was considered significant. SPSS software (version 18.0; SPSS Inc, Chicago, IL, USA) was used for all analyses.

Statistical power was calculated using G*Power 3.1, and the primary outcome was defined as time to first defibrillation (seconds). Mean time to the first defibrillation showed 81, 61, and standard deviations were 33.1, 24.3 in the conventional group and video call guidance group, respectively. Power was calculated as 0.948 based on an effect size d of 0.688162 and alpha error probability of less than 0.05 .

\section{Results}

The two groups of 48 teams were analyzed for their background characteristics. There were no significant differences in the sex, age, and years of work experience between the two groups (Table 1) and the appropriateness of defibrillation was $100 \%$ for both groups (Table 2). The median value of the time to the first defibrillation was significantly better in the video call guidance group (56s) than in the conventional group (73 s) $(\mathrm{p}<0.001)$. The median value of the total hands-off time was also significantly better ( 228 vs. $285.5 \mathrm{~s})(\mathrm{p}<0.001)$, and the hands-off ratio, defined as the proportion of hands-off time out of the total CPR time, was significantly shorter in the video call guidance group ( 0.32 vs. 0.41$)(\mathrm{p}<0.001)$ (Table 2$)$. 
TABLE 1: General characteristics of the study groups.

\begin{tabular}{lccc}
\hline & $\begin{array}{c}\text { Conventional } \\
\text { group }\end{array}$ & $\begin{array}{c}\text { Video call } \\
\text { guidance group }\end{array}$ & p-value \\
\hline Male sex, $\mathrm{n}(\%)$ & $97(67.4)$ & $102(70.8)$ & 0.85 \\
Mean age, years (range) & $32(25 \sim 43)$ & $33(27 \sim 42)$ & 0.89 \\
$\begin{array}{l}\text { Ethnicity } \\
\text { Asian, } \mathrm{n}(\%)\end{array}$ & $144(100 \%)$ & $144(100 \%)$ & \\
$\begin{array}{l}\text { Body Mass Index, } \mathrm{kg} / \mathrm{m}^{2} \\
\text { (mean } \pm \mathrm{SD})\end{array}$ & $23.4 \pm 5.1$ & $23.9 \pm 4.8$ & 0.79 \\
$\begin{array}{l}\text { Working experience, years } \\
\text { (mean } \pm \text { SD) }\end{array}$ & $3.7 \pm 1.5$ & $3.6 \pm 1.3$ & 0.72 \\
BLS provider, $\mathrm{n}(\%)$ & $134(93.0)$ & $130(90.3)$ & 0.88 \\
\hline
\end{tabular}

SD: standard deviation, BLS: basic life support.

TABLE 2: Cardiopulmonary resuscitation performance.

\begin{tabular}{|c|c|c|c|}
\hline & $\begin{array}{c}\text { Conventional } \\
\text { group } \\
(48 \text { teams }) \\
\end{array}$ & $\begin{array}{c}\text { Video call } \\
\text { guidance group } \\
\text { (48 teams) }\end{array}$ & $p$-value \\
\hline Accurate $\mathrm{D} / \mathrm{C}$ shock & & & 1.00 \\
\hline Yes & $48(100 \%)$ & $48(100 \%)$ & \\
\hline No & $0(0 \%)$ & $0(0 \%)$ & \\
\hline Time to 1st defibrillation (seconds) & $73(59.75 \sim 90)$ & $56(44 \sim 74.25)$ & $<0.001$ \\
\hline $\begin{array}{l}\text { Time from last compression to } \\
\text { defibrillation (seconds) }\end{array}$ & $8(3 \sim 19)$ & $3(2 \sim 7)$ & $<0.001$ \\
\hline $\begin{array}{l}\text { Time from defibrillation to chest } \\
\text { compression (seconds) }\end{array}$ & $3(2 \sim 4)$ & $2(1 \sim 3)$ & $<0.001$ \\
\hline Total CPR time (seconds) & $704.5(674 \sim 740)$ & $686.5(663 \sim 706.2)$ & 0.004 \\
\hline Total hands-off time (seconds) & $\begin{array}{c}285.5 \\
(299.75 \sim 339.0)\end{array}$ & $\begin{array}{c}228 \\
(192.75 \sim 270.25)\end{array}$ & $<0.001$ \\
\hline $\begin{array}{l}\text { Hands-off ratio (total hands-off } \\
\text { time/total CPR time (seconds) }\end{array}$ & $0.41(0.33 \sim 0.47)$ & $0.32(0.27 \sim 0.38)$ & $<0.001$ \\
\hline
\end{tabular}

The values (except accurate $\mathrm{D} / \mathrm{C}$ shock) are presented as the median (interquartile range).

BLS: basic life support, D/C: direct current, CPR: cardiopulmonary resuscitation.

In terms of the secondary outcomes, the median value of the time from the last compression to defibrillation was significantly shorter in the video call guidance group (3 [IQR 2-7] s) than in the conventional group (8 [IQR 3-19] s) $(\mathrm{p}<0.001)$, as was the median value of the time from defibrillation to resumed chest compression (2 [IQR 1-3] vs. 3 [IQR 2-4] s) $(\mathrm{p}<0.001)$ (Table 2).

\section{Discussion}

This study investigated the effects of physician-guided CPR via video calls and the use of manual defibrillators in outof-hospital cardiac arrest situations where an emergency physician is not dispatched. Our results showed that the video call guidance group had significantly better performance in terms of the time to first defibrillation, hands-off time, handsoff ratio, time from the last compression to defibrillation, and time from defibrillation to resumed compression.

South Korea has a considerably lower rate of successful resuscitation by CPR than other developed countries, such as the United States and Japan, with one reason being the low success rate of prehospital resuscitation. Considering that the average time for the paramedics to arrive at the scene is about 7-8 minutes, the successful resuscitation rate should be about $6-7 \%$ [1], highlighting the need to improve the quality of prehospital CPR. As one measure to address this issue, studies have sought to improve the quality of bystander CPR by facilitating communication between the dispatcher and bystander using voice and video calls, with video-assisted communication showing superior outcomes over voice calls $[13,14]$. According to a study by Yang et al., the group using video calls showed better outcomes regarding securing and maintaining open airways, appropriate chin lift, and ventilation volume [13]. Moreover, one previous study reported that having eye-contact with a dispatcher through a video call and being supervised and directed by the dispatcher increased the confidence of lay rescuers in highly stressful emergency situations [14]. Tränkler et al. investigated whether it was possible to obtain an adequate understanding of the CPR scene through a $3 \mathrm{G}$ video call and concluded that $3 \mathrm{G}$ video calls were indeed sufficient 
in relaying accurate information about the CPR scene with appropriate distance between the camera and object, angle, and lighting [15]. However, these studies were all conducted in the general population, and, to date, no existing study has examined paramedic performance under direct physician guidance using long-term evolution video calls. In this study, the video call guidance group showed significantly better performance in the time to first defibrillation (56s) than the conventional group (73 s) $(\mathrm{p}<0.001)$. These positive results support the recent CPR guidelines in which the importance of performing defibrillation as quickly as possible is stressed [16] and indicate that dispatchers can provide quicker analysis and directions than AEDs.

The longer the hands-off time is, the more the blood flow to the heart and brain is reduced, and the lower the probability of ROSC is, suggesting that chest compression pauses should be kept at a minimum [17, 18]. Currently, manual defibrillators are legally prohibited for use by the Emergency Medical Services in South Korea. In our study, an emergency physician confirmed the rhythm of the manual defibrillators and directed defibrillation via a video call, and the group that received such directions showed superior performance compared to the conventional group in the hands-off time, and hands-off ratio, corroborating the results of previous studies that compared CPR using AEDs and manual defibrillators $[10,11]$. Furthermore, in our study, the time from last compression to defibrillation and the time from defibrillation to resumed chest compression were significantly shorter in the video call guidance group, which is speculated to be due to the fact that the guiding emergency physician could quickly analyze the rhythms and continuously encouraged the paramedics to maintain constant chest compression.

This study has some limitations that need to be acknowledged. First, the quality of video calls may vary according to the LTE network quality and environmental factor; however, we did not investigate these differences in the present study.

Second, there may be differences between the simulated environment and the real situation. Third, since there are many kinds of AEDs and manual defibrillators, the outcome might be different from other kinds of defibrillators.

\section{Conclusions}

Physician-guided CPR with a video call enabled prompt manual defibrillation and significantly shortened the time required for first defibrillation, hands-off time, and hands-off ratio in simulated cases of prehospital cardiac arrest. These results should be verified in real clinical situations in the near future.

\section{Data Availability}

No data were used to support this study.

\section{Disclosure}

This study was presented in part at the 12th European Emergency Medicine Congress, Glasgow, United Kingdom,
8-12 September 2018, and the 31st Annual Congress of the European Society of Intensive Care Medicine, Paris, France, 20-24 October 2018.

\section{Conflicts of Interest}

The authors declare that they have no conflicts of interest.

\section{Authors' Contributions}

Conceptualization was done by S.M. Park. Data curation was carried out by D.K. Lee and Y.J. Kim. S.M. Park and Y.H. Lee did the formal analysis and S.M. Park did the investigation. Methodology was made by Y.H. Lee. Project administration was done by Y.H. Lee. Y.H. Lee collected the resources and S.M. Park did the supervision. Validation has been carried out by S.M. Park, G.W. Kim, and J.W. Jeong. D.K. Lee did the visualization and writing of the original draft. Y.H. Lee, S.M. Park, and D.H. Shin did the revision and editing. Seung Min Park and Young Hwan Lee contributed equally to this work.

\section{Acknowledgments}

This work was supported by the Soonchunhyang University Research Fund.

\section{References}

[1] Survey of Acute Cardiac Arrest, Ministry of Health and Welfare, Republic of Korea,.

[2] B. McNally, R. Robb, M. Mehta et al., "Out-of-hospital cardiac arrest surveillance-cardiac arrest registry to enhance survival (CARES), United States, October 1, 2005-December 31, 2010," MMWR Surveillance Summaries, vol. 60, pp. 1-19, 2011.

[3] S. D. Shin, T. Kitamura, S. S. Hwang et al., "Association between resuscitation time interval at the scene and neurological outcome after out-of-hospital cardiac arrest in two asian cities," Resuscitation, vol. 85, no. 2, pp. 203-210, 2014.

[4] A. Gries, W. Zink, M. Bernhard, M. Messelken, and T. Schlechtriemen, "Realistic assessment of the physican-staffed emergency services in Germany," Der Anaesthesist, vol. 55, no. 10, pp. 1080-1086, 2006.

[5] G. Prause, G. Wildner, J. Kainz et al., "Strategies for quality assessment of emergency helicopter rescue systems. The Graz model," Der Anaesthesist, vol. 56, no. 5, pp. 461-465, 2007.

[6] C. D. Deakin, D. Murphy, M. Couzins, and S. Mason, "Does an advanced life support course give non-anaesthetists adequate skills to manage an airway?" Resuscitation, vol. 81, no. 5, pp. 539543, 2010.

[7] S. Sollid, M. Sandberg, A. Nakstad, and P. Bredmose, "Do anaesthesiologists in pre-hospital care need concomitant clinical practice?" Scandinavian Journal of Trauma, Resuscitation and Emergency Medicine, vol. 21, no. Suppl 1, p. S7, 2013.

[8] H. E. Wang, G. K. Balasubramani, L. J. Cook, J. R. Lave, and D. M. Yealy, "Out-of-hospital endotracheal intubation experience and patient outcomes," Annals of Emergency Medicine, vol. 55, no. 6, pp. 527-e6, 2010.

[9] A. Von Goedecke, H. Herff, P. Paal, V. Dörges, and V. Wenzel, "Field airway management disasters," Anesthesia \& Analgesia, vol. 104, no. 3, pp. 481-483, 2007. 
[10] M. Pytte, T. E. Pedersen, J. Ottem, A. S. Rokvam, and K. Sunde, "Comparison of hands-off time during CPR with manual and semi-automatic defibrillation in a manikin model," Resuscitation, vol. 73, no. 1, pp. 131-136, 2007.

[11] J. Kramer-Johansen, D. P. Edelson, B. S. Abella, L. B. Becker, L. Wik, and P. A. Steen, "Pauses in chest compression and inappropriate shocks: A comparison of manual and semi-automatic defibrillation attempts," Resuscitation, vol. 73, no. 2, pp. 212-220, 2007.

[12] J. S. Lee, W. C. Jeon, J. H. Ahn, Y. J. Cho, Y. S. Jung, and G. W. Kim, "The effect of a cellular-phone video demonstration to improve the quality of dispatcher-assisted chest compressiononly cardiopulmonary resuscitation as compared with audio coaching," Resuscitation, vol. 82, no. 1, pp. 64-68, 2011.

[13] C.-W. Yang, H.-C. Wang, W.-C. Chiang et al., "Impact of adding video communication to dispatch instructions on the quality of rescue breathing in simulated cardiac arrests-A randomized controlled study," Resuscitation, vol. 78, no. 3, pp. 327-332, 2008.

[14] S. R. Bolle, E. Johnsen, and M. Gilbert, "Video calls for dispatcher-assisted cardiopulmonary resuscitation can improve the confidence of lay rescuers - surveys after simulated cardiac arrest," Journal of Telemedicine and Telecare, vol. 17, no. 2, pp. 88-92, 2011.

[15] U. Tränkler, O. Hagen, and A. Horsch, "Video quality of 3G videophones for telephone cardiopulmonary resuscitation," Journal of Telemedicine and Telecare, vol. 14, no. 7, pp. 396-400, 2008.

[16] M. E. Kleinman, E. E. Brennan, Z. D. Goldberger et al., "Part 5: adult basic life support and cardiopulmonary resuscitation quality: 2015 American Heart Association guidelines update for cardiopulmonary resuscitation and emergency cardiovascular care," Circulation, vol. 132, no. 18, pp. S414-S435, 2015.

[17] R. A. Berg, A. B. Sanders, K. B. Kern et al., "Adverse hemodynamic effects of interrupting chest compressions for rescue breathing during cardiopulmonary resuscitation for ventricular fibrillation cardiac arrest," Circulation, vol. 104, no. 20, pp. 24652470, 2001.

[18] T. Eftestøl, K. Sunde, and P. A. Steen, "Effects of interrupting precordial compressions on the calculated probability of defibrillation success during out-of-hospital cardiac arrest," Circulation, vol. 105, no. 19, pp. 2270-2273, 2002. 


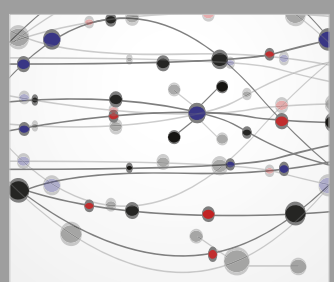

The Scientific World Journal
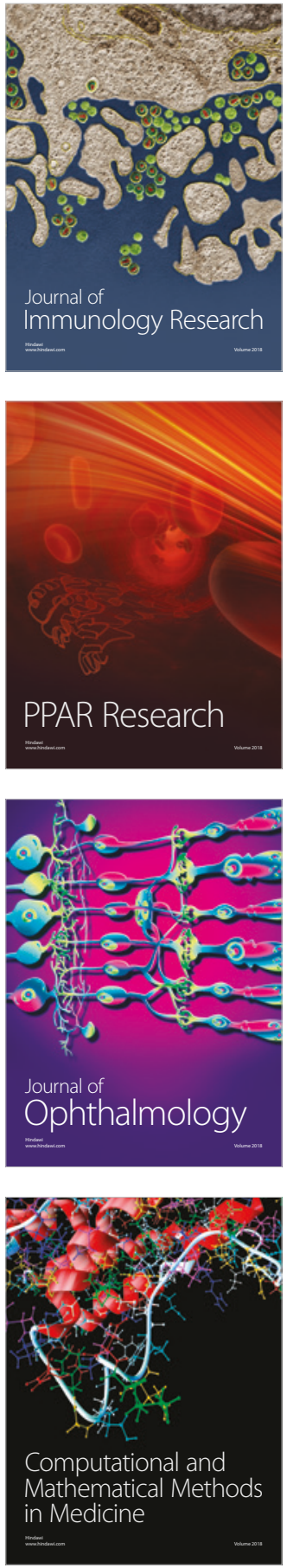

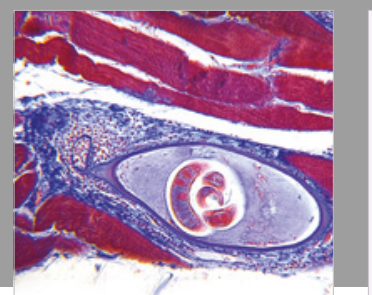

Gastroenterology Research and Practice

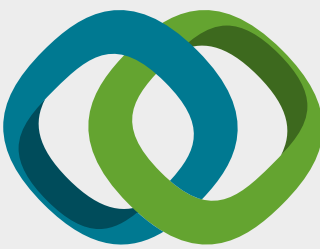

\section{Hindawi}

Submit your manuscripts at

www.hindawi.com
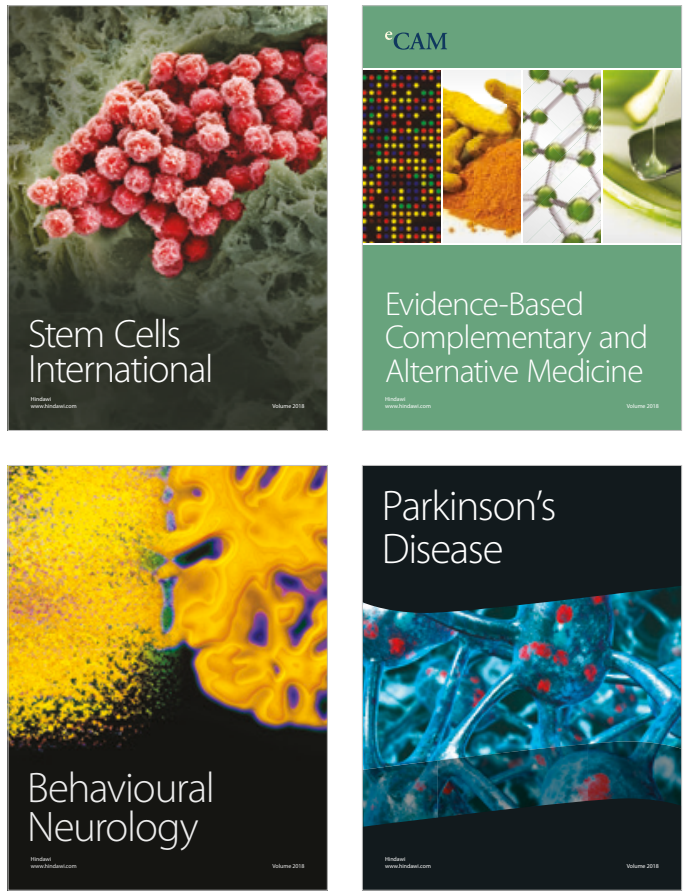

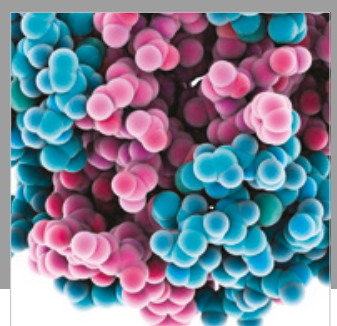

ournal of

Diabetes Research

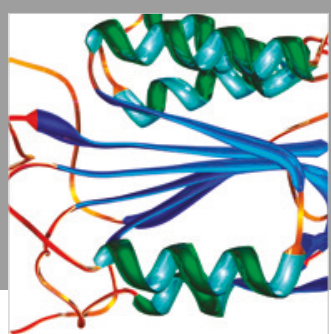

Disease Markers
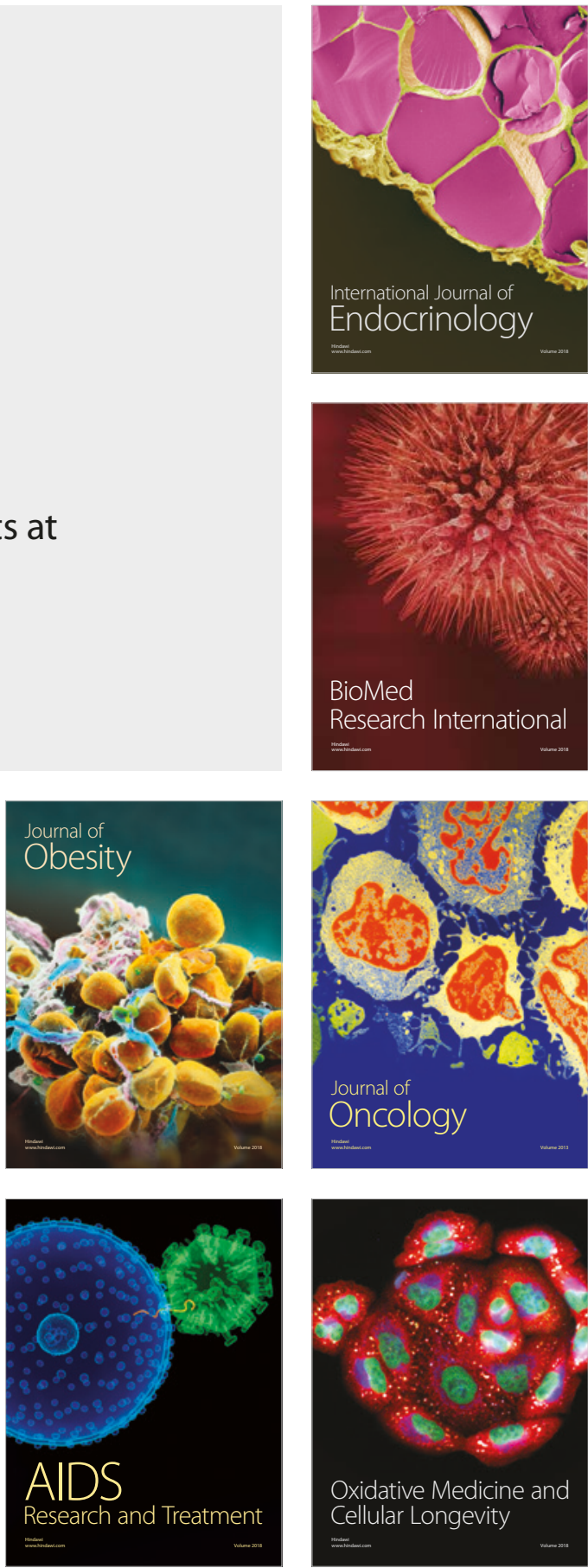